Agrotrópica 32(2): 111 - 118. 2020.

Centro de Pesquisas do Cacau, Ilhéus, Bahia, Brasil

\title{
INFLUÊNCIA DA IDADE DA FOLHA DE Hevea brasiliensis (Euphorbiaceae) NA OVIPOSIÇÃO E PARASITISMO DE OVOS DE Leptopharsa heveae (HEMIPTERA: TINGIDAE)
}

\author{
Rodrigo Souza Santos \\ Embrapa Acre. Rod. BR 364, km 14, CP 321, 69900-970, Rio Branco, AC, Brasil. rodrigo.s.santos@embrapa.br
}

\begin{abstract}
Ninfas e adultos de Leptopharsa heveae sugam a seiva das folhas de seringueira, causando prejuízos econômicos de até $30 \%$ na produção de látex. O ataque de insetos fitófagos é influenciado por características (química e/ou físicas) da planta hospedeira. Esse estudo visou determinar a influência de folhas novas, intermediárias e maduras, na oviposição de L. heveae e no parasitismo de Erythmelus tingitiphagus. Semanalmente, eram escolhidas aleatoriamente cinco plantas de cada clone, de onde eram retiradas nove folhas (três de cada idade) dos clones PB 217, PB 235, PR 255, RRIM 600 e GT1. Em laboratório as folhas eram lavadas em hipoclorito de sódio (1,5\%), sendo destacado um folíolo por folha. Sob microscópio estereoscópio, procedia-se a demarcação dos ovos de L. heveae com caneta à prova d'água. Posteriormente, os folíolos eram acondicionados em sacos plásticos inflados, com auxílio de um compressor de ar, selados e pendurados em varais em sala climatizada $\left(25 \pm 1^{\circ} \mathrm{C}\right.$ e fotofase de 12 horas). A avaliação procedia-se após cinco dias, contabilizando o número de parasitoides emergidos sob microscópio estereoscópico. Verificou-se que o número de ovos de L. heveae e a taxa de parasitismo de E. tingitiphagus foram superiores em folíolos maduros para todos os clones estudados.
\end{abstract}

Palavras-chave: Chalcidoidea, interação inseto-planta, Mymaridae, percevejo-de-renda.

Influence of Hevea brasiliensis leaf age on the oviposition and parasitism of Leptopharsa heveae (Hemiptera: Tingidae) eggs. Nymphs and adults of Leptopharsa heveae suck the sap from the rubber tree leaves, causing economic losses of up to $30 \%$ in latex production. The attack of phytophagous insects is influenced by characteristics (chemical and/or physical) of the host plant. This study aimed to determine the influence of new, intermediate and mature leaves, on the oviposition of L. heveae and on the parasitism of Erythmelus tingitiphagus. Weekly, five plants from each clone were chosen randomly, from which nine leaves (three of each age) were taken from clones PB 217, PB 235, PR 255, RRIM 600 and GT1. In the laboratory, the leaves were washed in sodium hypochlorite $(1.5 \%)$, with one leaflet per leaf. Under a stereomicroscope, $L$. heveae eggs were demarcated with a waterproof pen. Posteriorly, the leaflets were packed in inflated plastic bags, with the aid of an air compressor, sealed and hung on clotheslines in an acclimatized room $\left(25 \pm 1{ }^{\circ} \mathrm{C}\right.$ and 12 hour photophase). The evaluation was carried out after five days, counting the number of parasitoids emerged under a stereomicroscope. It was found that the number of L. heveae eggs and the parasitism rate of E. tingitiphagus were higher in mature leaflets for all studied clones.

Key words: Chalcidoidea, insect-plant interaction, Mymaridae, lace bug. 


\section{Introdução}

Durante o transcorrer da evolução, boa parte dos insetos tornou-se mais especializada em seu comportamento alimentar através da adaptação a certas plantas hospedeiras, ou mesmo por meio da adaptação ao micro-habitat fornecido pela morfologia das plantas, provavelmente devido à competição interespecífica por alimento e abrigo (Lara, 1991). Em resposta ao ataque dos insetos, as plantas adquiriram diversos mecanismos para resistir a este ataque, apresentando características físicas e, ou, químicas que atuam negativamente na alimentação, metabolismo e reprodução dos insetos (Painter, 1951; Lara, 1991; Vendramim e Guzzo, 2009).

Plantas mais novas são, geralmente, consideradas mais susceptíveis aos insetos em detrimento ao seu estágio menos desenvolvido, mas isso nem sempre ocorre e, em muitos casos, tem-se observado um comportamento inverso. Assim, nota-se que há diferentes comportamentos das plantas em relação à idade. Este aspecto é válido para todas as partes ou órgãos da planta (Lara, 1991).

Os insetos atacam as plantas com diferentes intensidades, dependendo da fase de desenvolvimento em que ela se encontra (Lara, 1991), por fatores relacionados com características das folhas (Ganzhorn, 1995), arquitetura da planta (Price et al., 1995) e diferentes microclimas na copa, em virtude dos efeitos do vento, da temperatura e da radiação solar sobre a planta (Bernays \& Chapman, 1994; Alonso, 1997). As relações tritróficas envolvendo plantas, pragas e inimigos naturais são importantes e derivam de vários fatores, que podem ser resumidos, basicamente, como resultantes de três tipos de efeitos: (a) efeito direto da planta sobre a biologia e, ou, o comportamento do inimigo natural devido a substâncias químicas ou características morfológicas presentes na planta; (b) efeito da planta sobre a praga alterando o comportamento, o desenvolvimento, o tamanho e o vigor, o que, indiretamente, também afeta o inimigo natural e (c) produção de compostos secundários voláteis liberados pelas plantas, em resposta ao ataque de um herbívoro, os quais podem atrair predadores ou parasitoides da praga (Vendramim, 2002; Voelckel \& Badwin, 2004).

Essas interações podem explicar as variações no parasitismo ou predação em função da planta ou variedade em que a praga está se alimentando (Lara et al., 1997) e, se tornam ainda mais complexas quando há mais de uma espécie de inimigo natural presente, situação que leva à ocorrência de sucessões tróficas capazes de afetar o comportamento e a biologia de cada organismo envolvido (Venzon et al., 2001).

Normalmente, os insetos escolhem as plantas de acordo com seu conteúdo nutricional, sendo as folhas e flores jovens frequentemente preferidas (AlmeidaCortez, 2005). No entanto, a alimentação de insetos sugadores depende do estágio de desenvolvimento da planta hospedeira, do tecido consumido e da parte específica da planta onde o inseto realiza o ataque (Begon, Mortimer \& Thompson, 1996; Crawley, 1997; Stiling, 2001; Boege \& Marquis, 2005).

Nesse sentido, este trabalho objetivou verificar a influência da idade de folhas de seringueira sobre a oviposição de Leptopharsa heveae Drake \& Poor (Hemiptera: Tingidae) e o parasitismo de seus ovos por Erythmelus tingitiphagus (Soares) (Hymenoptera: Mymaridae).

\section{Material e Métodos}

O estudo foi realizado no período de outubro de 2005 a fevereiro de 2006, no Jardim Clonal (Quadra 510 A) da fazenda da empresa Plantações Edouard Michelin Ltda., localizada no município de Itiquira, Mato Grosso, Brasil (17²2’23”'S, 5444'23”O).

\section{Caracterização da área}

\section{Quadra 510 A (Jardim Clonal)}

Foram amostradas folhas de seringueiras dos clones RRIM 600, PR 255, GT 1, PB 235 e PB 217, cultivados em regime tradicional de monocultivo, com nove anos de idade, altura média das árvores de três metros e espaçamento de 1,0 x 1,5 x 4 m (linhas duplas). O Jardim Clonal ocupa uma área de aproximadamente 0,8 ha sendo utilizado como fonte de "cavalos" para enxertia, sofrendo podas periódicas. Os lados Leste e Oeste do talhão fazem limite com plantas de Arachis sp. (Fabaceae) (amendoim-forrageiro).

A área de estudo sofreu ataque do fungo Microcyclus ulei (P. Henn.) (Dothideaceae), causador da doença conhecida como "mal-das-folhas" em dezembro de 2015. Nesta ocasião, as árvores receberam tratamento fitossanitário com fungicida no 
final do mês de dezembro de 2005 e início de janeiro de 2006. Foram realizadas 16 coletas semanais no período do estudo, no entanto, não foram coletadas folhas novas e de idade intermediária durante o período de ataque do fungo, pois as folhas dessas idades estavam impróprias para o ensaio. Assim, no caso de folhas novas e intermediárias, foram realizadas 10 amostragens.

A cada coleta eram escolhidas aleatoriamente cinco plantas de cada clone e, de cada uma, eram coletadas nove folhas, sendo três novas (folíolos de coloração arroxeada a verde-claro e não expandidos), três intermediárias (folíolos de coloração verde-claro e semiexpandidos) e três maduras (folíolos de coloração verdeescuro e completamente expandidos) (Figuras $1 \mathrm{~A} \mathrm{a} \mathrm{C),}$ do terço inferior da copa, totalizando 45 folhas por clone. A distribuição de ninfas e adultos de $L$. heveae nas folhas de seringueira, dá-se de maneira similar nos diferentes estratos da planta, não comprometendo a amostragem vertical (Cividanes, Fonseca e Santos, 2004).

As folhas eram acondicionadas em sacos de papel identificados e levadas ao laboratório para posterior avaliação. De cada folha era retirado aleatoriamente um folíolo, por idade e por árvore, totalizando nove folíolos por árvore (três novos, três intermediários e três maduros) e 45 folíolos por clone. Todos os folíolos foram submetidos à lavagem em solução de hipoclorito de sódio a 1,5\% durante dois minutos, para

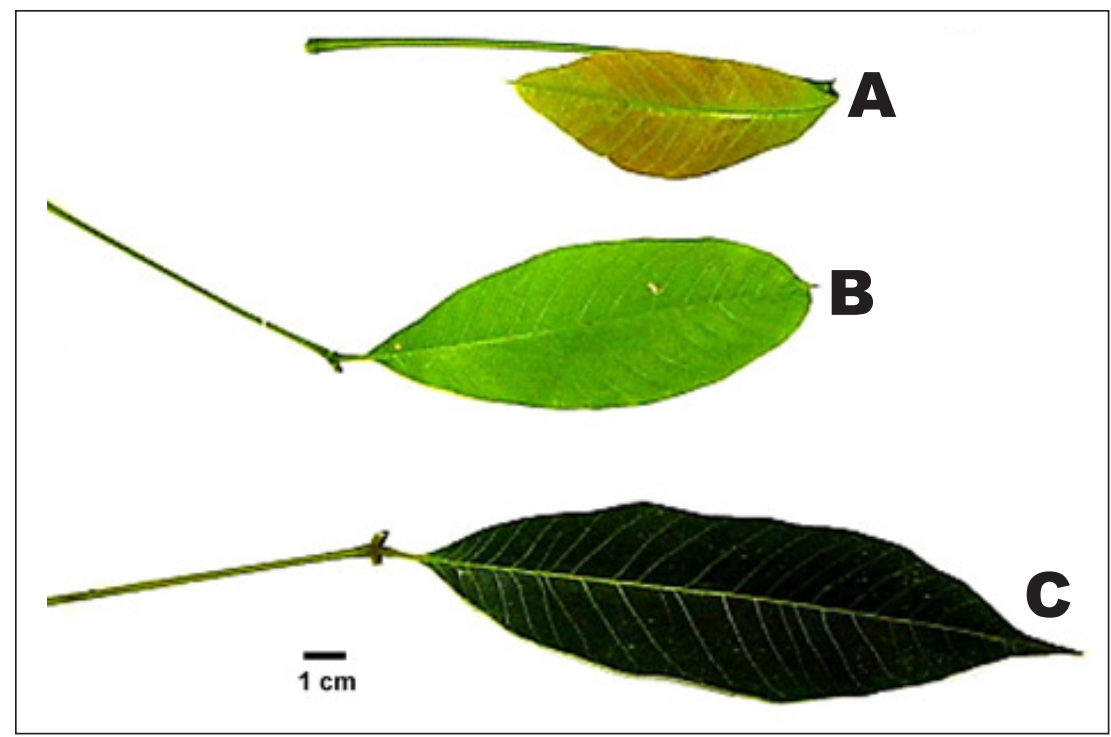

Figura 1. Folíolos de seringueira em três idades distintas: A. folíolo novo; B. folíolo intermediário; C. folíolo maduro. (Crédito das fotos: Rodrigo Souza Santos). remoção de impurezas e/ou ovos de outros insetos que poderiam estar presentes na superfície dos mesmos. Após, foram enxaguados em água destilada por dois minutos e mantidos em papel absorvente até a secagem.

\section{Avaliação da oviposição de Leptopharsa heveae}

Era escolhido, aleatoriamente, um folíolo de cada idade para quantificação dos ovos de L. heveae (um folíolo por idade/planta, sendo cinco folíolos por idade/clone/coleta), sendo as áreas contendo ovos demarcadas com caneta à prova d'água, de acordo com metodologia adaptada do trabalho de Costa, Pereira e Batista Filho, (2003).

O total de folíolos amostrados foi de 50 folíolos novos, 50 intermediários e 80 folíolos maduros, por planta em todas as avaliações realizadas durante o período de estudo.

\section{Avaliação do parasitismo de Erythmelus tingitiphagus}

A cada amostragem era avaliada a emergência de parasitoides em 45 folíolos por clone ( 15 folíolos por idade de folha/planta/coleta).

Durante o período de estudo foram analisados um total de 150 folíolos novos, 150 intermediários e 240 folíolos maduros.

Os pecíolos de cada folíolo foram colocados em tubos plásticos contendo água destilada, tendo sua abertura lacrada com Parafilm $\mathbf{M}^{\circledR}$. Esse material (tubos + folíolos) foi colocado em sacos plásticos $(12 \mathrm{x}$ $30 \mathrm{~cm}$ ) identificados, enchidos com um compressor de ar e selados com auxílio de uma seladora elétrica (Santos e Freitas, 2008a). Os sacos foram transferidos para uma sala climatizada a $25 \pm 1{ }^{\circ} \mathrm{C}$ e fotofase de 12 horas e pendurados em varais, com auxílio de prendedores.

A avaliação procedeu-se após cinco dias, observando-se os sacos e folíolos sob microscópio estereoscópico, verificando a presença dos parasitoides. Com auxílio de instrumento pontiagudo, os ovos não eclodidos eram 
dissecados à procura de parasitoides não emergidos. A porcentagem de parasitismo foi obtida pelo número total de indivíduos coletados (inclusive os não emergidos), dividindo pelo número total de ovos e multiplicando o valor por 100 .

Os parasitoides encontrados foram preservados em frascos de vidro contendo etanol (80\%) e enviados para os taxonomistas Dr. Valmir Antonio Costa (Instituto Biológico, Campinas, SP) e Dra. Ranyse Barbosa Querino da Silva (Embrapa, Brasília, DF) para identificação ao menor nível taxonômico possível.

\section{Resultados e Discussão}

Foi contabilizado um total de 2.009 ovos de $L$. heveae entre os diferentes estádios fenológicos dos folíolos coletados entre todos os clones estudados, com média de 11,2 ovos/folíolo. Destes, 874 foram contabilizados no clone PR 255, 364 no RRIM 600, 359 no GT1, 324 no PB 235 e 88 no PB 217. O maior número de ovos de L. heveae foi registrado nas folhas maduras em todos os clones, em relação às intermediárias e novas, com 1.723, 247 e 39 ovos, respectivamente (Tabela 1).
Os folíolos novos, caracterizados por terem uma área superficial menor, possuírem maior flexibilidade e menor espessura cuticular, praticamente não apresentaram ovos de L. heveae, à exceção de plantas do clone PR 255, onde foi possível verificar a presença de 34 ovos (Tabela 1). Segundo o verificado por Santos et al. (1999), utilizando microscopia eletrônica de varredura, a superfície dos folíolos jovens do clone de seringueira PB 86 difere da dos adultos por possuir a cutícula muito fina, tanto na face adaxial quanto na abaxial.

Os folíolos de idade intermediária apresentaram maior incidência de ovos quando comparados aos novos. O número de ovos de L. heveae foi sempre superior em folíolos maduros em relação aos intermediários e novos em todos os clones estudados, variando de 664 para o clone PR 255 e 76 para o PB 217 (Tabela 1).

Lara \& Tanzini (1997) observaram uma não preferência por alimentação de $L$. heveae, para os clones FX 4037, RO 38, RO 46 e preferência nos clones GT 1 e IAN 873. Via de regra, se a planta hospedeira oferece os nutrientes necessários para o desenvolvimento de insetos herbívoros/fitófagos, estes

Tabela 1. Número de ovos de Leptopharsa heveae, espécimes de Erythmelus tingitiphagus e porcentagem de parasitismo em folíolos novos, intermediários e maduros, em cinco clones de seringueiras, no município de Itiquira, MT

\begin{tabular}{|c|c|c|c|c|c|c|c|c|c|c|c|c|c|c|c|}
\hline \multirow{3}{*}{ MESES } & \multicolumn{3}{|c|}{ PB 217} & \multicolumn{3}{|c|}{ PB 235} & \multicolumn{3}{|c|}{ RRIM 600} & \multicolumn{3}{|c|}{ GT 1} & \multicolumn{3}{|c|}{ PR 255} \\
\hline & \multicolumn{15}{|c|}{ Leptopharsa heveae (ovos) / Erythmelus tingitiphagus (n) } \\
\hline & FN & FI & FM & FN & FI & FM & FN & FI & FM & FN & FI & FM & $\mathbf{F N}$ & FI & FM \\
\hline out/05 & $0 / 0$ & $0 / 0$ & $1 / 1$ & $0 / 0$ & $3 / 0$ & $4 / 0$ & $0 / 0$ & $2 / 0$ & $2 / 0$ & $0 / 0$ & $2 / 0$ & $12 / 3$ & $0 / 0$ & $24 / 0$ & $10 / 4$ \\
\hline out/05 & $0 / 0$ & $0 / 0$ & $10 / 1$ & $0 / 0$ & $0 / 0$ & $10 / 2$ & $1 / 0$ & $4 / 0$ & $5 / 3$ & $0 / 0$ & $1 / 0$ & $10 / 3$ & $5 / 0$ & $6 / 0$ & $9 / 3$ \\
\hline nov/05 & $0 / 0$ & $0 / 0$ & $2 / 0$ & $0 / 0$ & $3 / 0$ & $12 / 3$ & $0 / 0$ & $5 / 0$ & $2 / 0$ & $0 / 0$ & $2 / 0$ & $10 / 2$ & $1 / 0$ & $4 / 0$ & $10 / 1$ \\
\hline nov/05 & $0 / 0$ & $0 / 0$ & $1 / 0$ & $3 / 0$ & $6 / 0$ & $20 / 4$ & $0 / 0$ & $0 / 0$ & $34 / 7$ & $1 / 0$ & $0 / 0$ & $19 / 5$ & $2 / 0$ & $14 / 1$ & $38 / 10$ \\
\hline nov/05 & $0 / 0$ & $9 / 0$ & $3 / 0$ & $0 / 0$ & $6 / 1$ & $23 / 3$ & $0 / 0$ & $2 / 0$ & $20 / 10$ & $0 / 0$ & $6 / 0$ & $39 / 15$ & $0 / 0$ & $3 / 0$ & $45 / 15$ \\
\hline nov/05 & $0 / 0$ & $3 / 0$ & $8 / 3$ & $0 / 0$ & $5 / 0$ & $21 / 7$ & $0 / 0$ & $1 / 0$ & $34 / 7$ & $0 / 0$ & $1 / 0$ & $3 / 1$ & $0 / 0$ & $10 / 0$ & $37 / 9$ \\
\hline $\mathrm{dez} / 05$ & $0 / 0$ & $0 / 0$ & $5 / 1$ & $0 / 0$ & $0 / 0$ & $8 / 0$ & $0 / 0$ & $0 / 0$ & $21 / 0$ & $0 / 0$ & $1 / 0$ & $10 / 1$ & $6 / 0$ & $18 / 0$ & $27 / 4$ \\
\hline $\mathrm{dez} / 05$ & $0 / 0$ & $0 / 0$ & $8 / 0$ & $0 / 0$ & $0 / 0$ & $49 / 11$ & $0 / 0$ & $0 / 0$ & $0 / 0$ & $0 / 0$ & $1 / 0$ & $35 / 8$ & $6 / 0$ & $7 / 0$ & $51 / 6$ \\
\hline $\mathrm{dez} / 05$ & $0 / 0$ & $0 / 0$ & $2 / 0$ & $0 / 0$ & $2 / 0$ & $20 / 1$ & $0 / 0$ & $0 / 0$ & $27 / 3$ & $0 / 0$ & $6 / 1$ & $37 / 10$ & $14 / 0$ & $90 / 3$ & $64 / 11$ \\
\hline $\mathrm{dez} / 05$ & $0 / 0$ & $0 / 0$ & $1 / 0$ & $0 / 0$ & $0 / 0$ & $13 / 2$ & $0 / 0$ & $0 / 0$ & $118 / 22$ & $0 / 0$ & $0 / 0$ & $32 / 4$ & $0 / 0$ & $0 / 0$ & $82 / 14$ \\
\hline $\mathrm{jan} / 06$ & $*$ & $*$ & $7 / 1$ & $*$ & $*$ & $23 / 4$ & $*$ & $*$ & $43 / 14$ & $*$ & $*$ & $20 / 4$ & $*$ & $*$ & $124 / 44$ \\
\hline $\mathrm{jan} / 06$ & $*$ & $*$ & $15 / 4$ & $*$ & $*$ & $48 / 13$ & $*$ & $*$ & $15 / 2$ & $*$ & $*$ & $95 / 17$ & $*$ & $*$ & $7 / 2$ \\
\hline $\mathrm{jan} / 06$ & $*$ & $*$ & $5 / 0$ & $*$ & $*$ & $19 / 11$ & $*$ & $*$ & $8 / 4$ & $*$ & $*$ & $7 / 1$ & $*$ & $*$ & $89 / 25$ \\
\hline $\mathrm{jan} / 06$ & $*$ & $*$ & $6 / 0$ & $*$ & $*$ & $7 / 3$ & $*$ & $*$ & $10 / 0$ & $*$ & $*$ & $5 / 0$ & $*$ & $*$ & $22 / 10$ \\
\hline $\mathrm{jan} / 06$ & $*$ & $*$ & $0 / 0$ & $*$ & $*$ & $3 / 1$ & $*$ & $*$ & $8 / 2$ & $*$ & $*$ & $2 / 0$ & $*$ & $*$ & $30 / 2$ \\
\hline $\mathrm{fev} / 06$ & $*$ & $*$ & $2 / 0$ & $*$ & $*$ & $16 / 2$ & $*$ & $*$ & $2 / 0$ & $*$ & $*$ & $2 / 1$ & $*$ & $*$ & $19 / 2$ \\
\hline TOTAL & $0 / 0$ & $12 / 0$ & $76 / 11$ & $3 / 0$ & $25 / 1$ & $296 / 67$ & $1 / 0$ & $14 / 0$ & $349 / 74$ & $1 / 0$ & $20 / 1$ & $338 / 75$ & $34 / 0$ & $176 / 4$ & $664 / 162$ \\
\hline \%Parasitismo & 0 & 0 & 14,5 & 0 & 4 & 22,6 & 0 & 0 & 21,2 & 0 & 5 & 22,2 & 0 & 2,3 & 24,4 \\
\hline
\end{tabular}

$\mathbf{F N}=$ Folíolo novo $; \mathbf{F I}=$ Folíolo intermediário $; \mathbf{F M}=$ Folíolo maduro $; *$ ausência de folíolos devido ao ataque do fungo Microcyclus ulei no Jardim Clonal. 
também a utilizarão como local de oviposição, principalmente no caso de insetos monófagos, como é o caso de L. heveae (Livingstone, 1977; Alves et al., 2006; Boiça Jr. et al., 2012; Jesus et al., 2013).

Características físicas e/ou químicas dos folíolos maduros possivelmente atuam positivamente na preferência alimentar e de oviposição de $L$. heveae por esta idade de folha. Estas características podem variar nas diferentes idades de folhas e dentre os clones, determinando as variações na taxa de oviposição encontradas. Santos (2014) verificou que há diferenças nas concentrações de fenóis totais em relação aos estádios fenológicos das folhas entre clones de seringueira e, que folhas novas possuem concentrações de fenóis totais superiores às folhas de idade intermediária e maduras.

Os compostos fenólicos (taninos, benzenoides, ligninas, flavonoides etc.), terpenoides (óleos essenciais, monoterpenos, sesquiterpenos, saponinas etc.) e compostos nitrogenados (alcaloides, glicosídeos cianogênicos, glicosinolatos etc.) (Carvalho, Gosmann e Schenkel, 2007; Ricklefs e Releya, 2016), podem provocar efeitos adversos nos insetos como deterrência alimentar ou de oviposição, redução da taxa de alimentação e capacidade de metabolização do alimento, além de depressão da sua função imune (Lill \& Marquis, 2001; Bruce \& Woodcock, 2005; Haviola et al., 2007). Dessa forma, o ataque de L. heveae em folíolos jovens de seringueira é menor, devido principalmente à deterrência alimentar pela maior concentração de compostos fenólicos presentes nos mesmos e, não pela sua resistência mecânica (espessura cuticular) ao aparelho bucal picador-sugador do percevejo-de-renda. Em consequência, folíolos novos são menos ovipositados, por apresentarem baixa qualidade alimentar ao inseto (compostos tóxicos), visto que esse é um fator preponderante para a reprodução dos mesmos (Panizzi e Silva, 2009).

As plantas também possuem mecanismos de defesa mecânica, tais como rigidez dos tecidos, presença de ceras, espinhos e tricomas, os quais reduzem o acesso dos insetos herbívoros/fitófagos aos tecidos vegetais (Vet, 1999). A principal defesa das espécies vegetais contra fatores abióticos e bióticos é sua superfície externa (Correa, 2007), coberta por substâncias lipídicas que compõem a denominada cutícula (Edwards e Wratten, 1981).
Constatou-se a ocorrência de inimigos naturais em populações de L. heveae nos cinco clones de seringueira estudados. Foram constatadas seis espécies de parasitoides, sendo E. tingitiphagus (Figura 2) a mais frequente e abundante, sendo o principal agente de controle biológico do percevejo-de-renda em condições de campo. As demais espécies ocorreram em baixa frequência e não foram constatadas em todos os clones (Tabela 2).

Foi contabilizado um total de 857 espécimes de $E$. tingitiphagus nos cinco clones estudados, sendo 356 no clone PR 255, 166 no GT1, 163 no RRIM 600, 140 no PB 235 e 32 no PB 217 (Tabela 1). Não foi observado parasitismo por E. tingitiphagus em folíolos novos, sendo constatado em folíolos intermediários e em maior número em folíolos maduros (Tabela 1). Possivelmente o baixo número de ovos encontrados em folíolos novos influenciou na ausência de parasitismo nesta idade de folha (Tabela 2).

O número médio de E. tingitiphagus, em folíolos maduros, variou de 21,7 no clone PR 255 e 2,0 no PB 217. Sempre foi verificada uma maior ocorrência do parasitoide em folíolos maduros em todos os clones, quando comparada à sua ocorrência em folíolos intermediários e novos. Isto pode ser explicado, pelo fato do número de oviposições de L. heveae ser muito superior em folíolos maduros, proporcionando uma

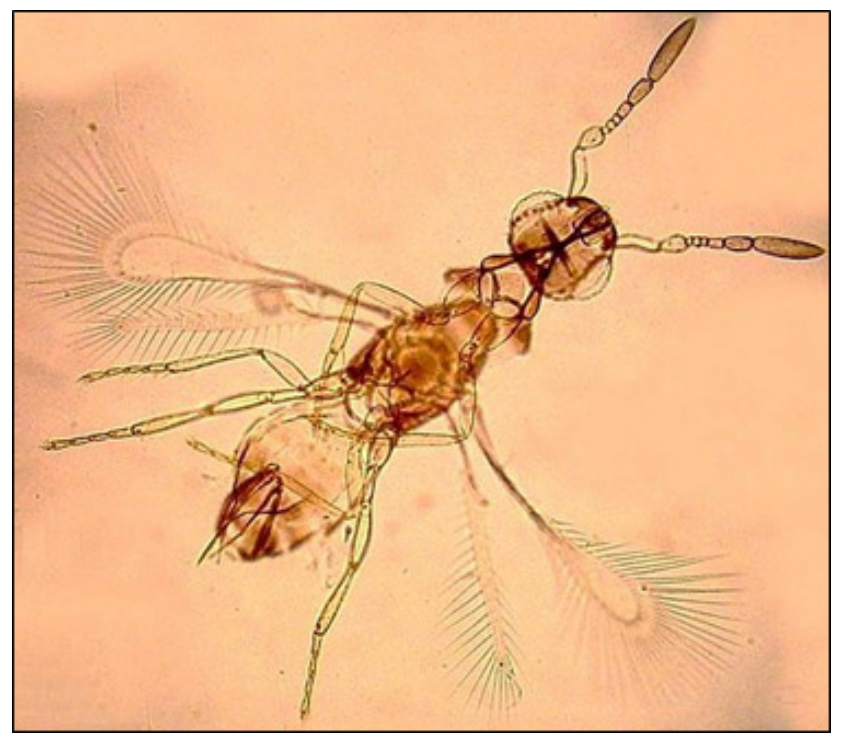

Figura 2. Fêmea adulta de Erythmelus tingitiphagus (Hymenoptera: Mymaridae). (Crédito da foto: Rodrigo Souza Santos). 
Tabela 2. Espécies de parasitoides registradas em cinco clones de seringueira, no período de outubro de 2005 a fevereiro de 2006, no município de Itiquira, MT

\begin{tabular}{lllr}
\hline Clone & Espécie de parasitoide & Família & $\mathbf{N}^{\mathbf{0}}$ de espécimes \\
\hline \multirow{3}{*}{ PB 217 } & Erythmelus tingitiphagus & Mymaridae & 32 \\
& Epoligosita mexicana & Trichogrammatidae & 3 \\
& Schizophragma bicolor & Aphelinidae & 2 \\
\hline \multirow{5}{*}{ PB 235 } & Erythmelus tingitiphagus & Mymaridae & 140 \\
& Epoligosita mexicana & Trichogrammatidae & 4 \\
& Eretmocerus sp. & Aphelinidae & 1 \\
& n.i. & Encyrtidae & 1 \\
\hline \multirow{5}{*}{ RRIM 600 } & Echizophragma bicolor & Mymaridae & 163 \\
& Epoligosita mexicana & Trichogrammatidae & 1 \\
\hline \multirow{2}{*}{ GT 1 } & Erythmelus tingitiphagus & Mymaridae & 7 \\
& Schizophragma bicolor & & 166 \\
\hline \multirow{5}{*}{ PR 255 } & Erythmelus tingitiphagus & & 1 \\
& Schizophragma bicolor & Mymaridae & 356 \\
& Epoligosita mexicana & Trichogrammatidae & 1 \\
& Eretmocerus sp. & Aphelinidae & 4 \\
& Encarsia sp. & Encyrtidae & 1 \\
& n.i. & & 1 \\
\hline
\end{tabular}

n.i. = não identificado maior disponibilidade de hospedeiros nesta idade de folha (Tabela 3), além das características físicas e/ou químicas presentes em cada uma das idades de folhas.

A porcentagem de parasitismo variou de $14,5 \%$ para o clone $\mathrm{PB}$ 217 a 24,4\% para o PR 255 em folíolos maduros e de 2,3\% no PR 255 a $5 \%$ no GT 1 em folíolos intermediários. Segundo Santos e Freitas (2008b), E. tingitiphagus apresentou uma taxa média de parasitismo de $24,2 \%$ em ovos de L. heveae (em folíolos maduros), para os clones RRIM 600, PR 255, PB 235, PB 217 e GT 1, em Itiquira, MT. Não foi verificado parasitismo em folíolos novos em todos os clones estudados, visto que folíolos dessa idade

Tabela 3. Número de espécimes de Erythmelus tingitiphagus em três idades diferentes de folíolos em cinco clones de seringueiras, no município de Itiquira, MT

\begin{tabular}{|c|c|c|c|c|c|c|c|c|c|c|c|c|c|c|c|}
\hline \multirow{3}{*}{ MESES } & \multicolumn{3}{|c|}{ PB 217} & \multicolumn{3}{|c|}{ PB 235} & \multicolumn{3}{|c|}{ RRIM 600} & \multicolumn{3}{|c|}{ GT 1} & \multicolumn{3}{|c|}{ PR 255} \\
\hline & \multicolumn{15}{|c|}{ Erythmelus tingitiphagus (n) } \\
\hline & FN & FI & FM & FN & FI & FM & FN & FI & FM & FN & FI & FM & FN & FI & FM \\
\hline out/05 & 0 & 0 & 1 & 0 & 0 & 2 & 0 & 0 & 6 & 0 & 0 & 11 & 0 & 0 & 10 \\
\hline out/05 & 0 & 0 & 3 & 0 & 0 & 3 & 0 & 0 & 3 & 0 & 0 & 14 & 0 & 0 & 7 \\
\hline nov/05 & 0 & 0 & 1 & 0 & 0 & 5 & 0 & 0 & 1 & 0 & 0 & 2 & 0 & 0 & 5 \\
\hline nov/05 & 0 & 0 & 1 & 0 & 0 & 6 & 0 & 0 & 14 & 0 & 0 & 7 & 0 & 0 & 29 \\
\hline nov/05 & 0 & 0 & 2 & 0 & 1 & 7 & 0 & 0 & 27 & 0 & 0 & 26 & 0 & 0 & 35 \\
\hline nov/05 & 0 & 0 & 10 & 0 & 0 & 12 & 0 & 0 & 15 & 0 & 0 & 4 & 0 & 2 & 22 \\
\hline $\mathrm{dez} / 05$ & 0 & 0 & 1 & 0 & 0 & 0 & 0 & 0 & 0 & 0 & 0 & 1 & 0 & 0 & 7 \\
\hline $\mathrm{dez} / 05$ & 0 & 0 & 0 & 0 & 0 & 12 & 0 & 0 & 0 & 0 & 0 & 11 & 0 & 2 & 15 \\
\hline $\mathrm{dez} / 05$ & 0 & 0 & 0 & 0 & 0 & 1 & 0 & 0 & 4 & 0 & 2 & 17 & 0 & 5 & 15 \\
\hline $\mathrm{dez} / 05$ & 0 & 0 & 2 & 0 & 0 & 2 & 0 & 0 & 37 & 0 & 0 & 9 & 0 & 0 & 22 \\
\hline $\mathrm{jan} / 06$ & $*$ & $*$ & 3 & $*$ & $*$ & 16 & $*$ & $*$ & 35 & $*$ & $*$ & 5 & $*$ & $*$ & 88 \\
\hline $\mathrm{jan} / 06$ & $*$ & $*$ & 6 & $*$ & $*$ & 16 & $*$ & $*$ & 6 & $*$ & $*$ & 49 & $*$ & $*$ & 7 \\
\hline $\mathrm{jan} / 06$ & $*$ & $*$ & 1 & $*$ & $*$ & 48 & $*$ & $*$ & 8 & $*$ & $*$ & 2 & $*$ & $*$ & 64 \\
\hline $\mathrm{jan} / 06$ & $*$ & $*$ & 1 & $*$ & $*$ & 3 & $*$ & $*$ & 3 & $*$ & $*$ & 3 & $*$ & $*$ & 13 \\
\hline $\mathrm{jan} / 06$ & $*$ & $*$ & 0 & $*$ & $*$ & 4 & $*$ & $*$ & 3 & $*$ & $*$ & 1 & $*$ & $*$ & 5 \\
\hline fev/06 & $*$ & $*$ & 0 & $*$ & $*$ & 2 & $*$ & $*$ & 1 & $*$ & $*$ & 2 & $*$ & $*$ & 3 \\
\hline TOTAL & 0 & 0 & 32 & 0 & 1 & 139 & 0 & 0 & 163 & 0 & 2 & 164 & 0 & 9 & 347 \\
\hline
\end{tabular}

FN = Folíolo novo $; \mathbf{F I}=$ Folíolo intermediário $; \mathbf{F M}=$ Folíolo maduro $; *$ folíolos não coletados devido ao ataque do fungo Microcyclus ulei no Jardim Clonal. 
praticamente não continham ovos de $L$. heveae, diminuindo a disponibilidade de hospedeiros ao parasitoide (Tabela 2).

\section{Conclusões}

A oviposição de L. heveae foi superior em folíolos de seringueira maduros em detrimento aos de idade intermediária e novos, em todos dos clones de seringueiras estudados.

A taxa de parasitismo de E. tingitiphagus foi maior em folíolos maduros de seringueira, em todos os clones de seringueiras estudados.

\section{Literatura Citada}

ALMEIDA-CORTEZ, J. S. 2005. Herbivoria e mecanismos de defesa vegetal. In: Nogueira, R. J. M. C. et al. (eds.). Estresses ambientais: danos e benefícios em plantas. Recife, Imprensa Universitária. pp.389-396.

ALONSO, C. 1997. Choosing a place to grow. Importance of whitin-plant abiotic microenvironment for Yponomeuta mahalebella. Entomologia Experimentalis et Applicata 83(2):171-180.

ALVES, A. C. et al. 2006. Atratividade e preferência para oviposição de Trialeurodes vaporariorum em genótipos de aboboeira. Horticultura Brasileira 24:446-449.

BEGON, M.; MORTIMER, M.; THOMPSON, D. J. 1996. Population Ecology: a unified study of animals and plants. $3^{\mathrm{a}}$ ed. Oxford, Blackwell Publishing. 256p.

BERNAYS, E. A.; CHAPMAN, R. F. 1994. Behavior: the importance of ecology and physiology. In: Bernays, E. A.; Chapman, R. F. (eds.). Host-plant selection by phytophagous insects. $2^{\mathrm{a}}$ ed. London, Chapman \& Hall. pp.166-205.

BOEGE, K.; MARQUIS, R. J. 2005. Facing herbivory as you grow up: the ontogeny of resistance in plants. Trends in Ecology \& Evolution 20(8):441-448.

BOIÇA JUNIOR, A. L. et al. 2012. Não preferência para oviposição e alimentação por Tuta absoluta (Meyrick) em genótipos de tomateiro. Arquivos do Instituto Biológico (Brasil) 79(4):541-548.

BRUCE, T. J. A.; WOODCOCK, C. W. 2005. Insect host location: a volatile situation. Trends in Plant Science 10:269-274.

CARVALHO, J. C. T.; GOSMANN, G.; SCHENKEL, E. P. 2007. Compostos fenólicos simples e heterosídicos. In: Simões, C. M. O. et al. (eds.). Farmacognosia: da planta ao medicamento. Porto Alegre. $6^{\mathrm{a}}$ ed. UFRGS, Florianópolis, SC, UFSC. pp.519-535.

CIVIDANES, F. J.; FONSECA F. S.; SANTOS, T. M. 2004. Distribuição de Leptopharsa heveae em seringal do Estado de São Paulo. Pesquisa Agropecuária Brasileira 39(10):1053-1056.

CORREA, P. G. 2007. Defesas foliares em resposta à herbivoria em espécies lenhosas de restinga, Ipojuca-PE. Dissertação Mestrado. Recife, PE, UFRPE. 54p.

COSTA, V. A.; PEREIRA, C. de F.; BATISTA FILHO, A. 2003. Observações preliminares sobre o parasitismo de ovos de Leptopharsa heveae (Hemiptera: Tingidae) em seringueira em Pindorama, SP. Arquivos do Instituto Biológico (Brasil) 70(2):205-206.

CRAWLEY, M. J. 1997. Plant-herbivores dynamics. In: Crawley, M. J. (Ed.). Plant ecology. $2^{a}$ ed. Oxford, Blackwell Publishing. pp.401-474.

EDWARDS, P. J.; WRATTEN, S. D. 1981. Ecologia das interações entre insetos e plantas. São Paulo, EPU, EDUSP. 71p.

GANZHORN, J. U. 1995. Low-level forest disturbance effects on primary production, leaf chemistry, and lemur populations. Ecology 76(7):2084-2096.

HAVIOLA, S. et al. 2007. Foliar phenolics are differently associated with Epirrita autumnata growth and immunocompetence. Journal of Chemical Ecology 33(5):1013-1023.

JESUS, F. G. et al. 2013. Desenvolvimento de Spodoptera eridania (Cramer) (Lepidoptera: Noctuidae) em diferentes hospedeiros. Arquivos do Instituto Biológico (Brasil) 80(4):430-435. 
LARA, M. F. 1991. Fatores que influenciam a manifestação da resistência. In: Lara, F. M. (ed.). Princípios de resistência de plantas a insetos. $2^{\mathrm{a}}$ ed. São Paulo, Ícone. pp.137-182.

LARA, F. M.; TANZINI, M. R. 1997. Nonpreference of the lace bug Leptopharsa heveae Drake \& Poor (Heteroptera, Tingidae) for rubber tree clones. Anais da Sociedade Entomológica do Brasil 26(3):429-434.

LARA, F. M. et al. 1997. Resistência de genótipos de sorgo a Contarinia sorghicola (Coq.) (Diptera: Cecidomyiidae) e Diatraea saccharalis (Fabr.) (Lepidoptera: Pyralidae) e influência sobre parasitóides. Anais da Sociedade Entomológica do Brasil 26(2):327-333.

LILL, J.; MARQUIS, T. 2001. The effects of leaf quality on herbivore performance and attack from natural enemies. Ecology 126:418-428.

LIVINGSTONE, D. 1977. Host specificity in Tingidae (Heteroptera) in relation to plants, parasitoids and predators. In: Ananthakrishman, T. N. (ed.). Insects and host-specificity. New Delhi, Mcmillan India. pp.23-28.

PAINTER, R. H. 1951. Insect resistance in crop plants. New York, McMillan. 520p.

PANIZZI, R. A.; SILVA F. A. C. 2009. Insetos sugadores de sementes (Heteroptera). In: Panizzi, R. A.; Parra J. R. P(Eds.). Bioecologia e nutrição de insetos: base para o manejo integrado de pragas. Brasília: Embrapa. pp.465-522.

PRICE, P. W. et al. 1995. Gradient analysis using plant modular structure: pattern in plant architecture and insect herbivore utilization. Environmental Entomology 24(3):497-505.

RICKLEFS, R.; RELEYA, R. 2016. A economia da natureza. $7^{\mathrm{a}}$ ed. Rio de Janeiro, Guanabara Koogan. 636p.

SANTOS, A. F. dos. et al. 1999. Importância da estrutura da superfície foliar na interação Phytophthora capsici - Hevea brasiliensis. Boletim de Pesquisa Florestal (Brasil) 39:67-80.

SANTOS, R. S. 2014. Quantificação de fenóis totais em cinco clones de seringueira, Hevea brasiliensis (Euphorbiaceae). In: Reunião Anual da SBPC, Rio Branco, AC, 66. 2014. Anais... Rio Branco, SBPC. 2p.

SANTOS, R. S.; FREITAS, S. de. 2008a. Parasitismo de Erythmelus tingitiphagus (Soares) (Hymenoptera: Mymaridae) em ovos de Leptopharsa heveae Drake \& Poor (Hemiptera: Tingidae), em plantios de seringueira (Hevea brasiliensis Müell. Arg.). Neotropical Entomology (Brasil) 37(5):571-576.

SANTOS, R. S.; FREITAS, S. de. 2008b. Erythmelus tingitiphagus (Hymenoptera: Mymaridae) um agente promissor no controle biológico do percevejo-de-renda (Hemiptera: Tingidae) da seringueira. Agrotrópica (Brasil) 20:25-28.

STILING, P. 2001. Ecology: theories and applications. $4^{\mathrm{a}}$ ed. New Jersey, Prentice-Hall. 403p.

VENDRAMIM, J. D. 2002. O controle biológico e a resistência de plantas. In: Parra, J. R. P. et al. (eds.). Controle biológico no Brasil: parasitóides e predadores. São Paulo, Manole. pp.511-521.

VENDRAMIM, J. D.; GUZZO, E. C. 2009. Resistência de plantas e a bioecologia e nutrição dos insetos. In: Panizzi, A. R.; Parra, J. R. P. (eds.). Bioecologia e nutrição de insetos: base para o manejo integrado de pragas. Brasília, DF, Embrapa Informação Tecnológica. pp.1055-1105.

VENZON, M.; PALLINI, A.; JANSSEN, A. 2001. Interactions mediated by predators in arthropod food webs. Neotropical Entomology (Brasil) 30(1):1-9.

VET, L. E. M. 1999. Evolutionary aspects of plantscarnivore interactions In: Chadwick, D. J.; Goode, J. A. (eds.). Insect-plant interactions and induced plant defense. Chichester, Novartis Foundation. pp.3-20.

VOELCKEL, C; BALDWIN, I. T. 2004. Herbivore induced plant vaccination. Part II. Array studies reveal the transience of herbivore specific transcriptional imprints and a distinct imprint from stress combinations.The Plant Journal 38(4):650-663. 